Article

\title{
The Trump Paradox: How Cues from a Disliked Source Foster Resistance to Persuasion
}

\author{
Alessandro Nai \\ Amsterdam School of Communication Research, University of Amsterdam, 1018 WV Amsterdam, The Netherlands; \\ E-Mail:a.nai@uva.nl
}

Submitted: 25 August 2019 | Accepted: 21 November 2019 | Published: 5 March 2020

\begin{abstract}
We usually reject information from sources we dislike. But what if those same sources explicitly disagree with that information? Are we more likely to be persuaded by information that is opposed by someone we dislike? We present results from an experimental study with a convenience sample of 199 Dutch students. Respondents were exposed to counterattitudinal information on climate change in an attempt to generate persuasion, and in a second time exposed to a tweet from the current US president, Donald J. Trump, as a positive or negative endorsement of the counter-attitudinal. Results show that positive endorsements reduce the persuasive power of counter-attitudinal information, whereas negative endorsements (marginally) increase its persuasive power. These results have important implications in today's politics, where "disliked" figures-most of the time referred to as "populists" - play an increasingly central role in framing the terms of the debate on the most salient issues.
\end{abstract}

\section{Keywords}

Donald Trump; political persuasion; populism; Twitter

Issue

This article is part of the issue "Leadership, Populism and Power" edited by Cristine de Clercy (Western University, Canada).

(C) 2020 by the author; licensee Cogitatio (Lisbon, Portugal). This article is licensed under a Creative Commons Attribution 4.0 International License (CC BY).

\section{Introduction}

Beyond politics and policy, one of the most defining elements of the Trump presidency is the blurring of the boundaries between official White House communications and personal outbursts from the President on social media. Trump's profuse use of Twitter - characterized by the trifecta of simplicity, impulsivity, and incivility (Ott, 2017) -is a central part of the narrative that portrays him as thin-skinned and quick to anger, deceitful, brazen, and boasting a grandiose sense of self and an exaggerated vision of his accomplishments. Several observers (Nai \& Maier, 2018, 2019; Visser, Book, \& Volk, 2017) have pointed to Trump's apparent narcissistic tendencies and his "sky-high extroversion combined with offthe-chart low agreeableness" (McAdams, 2016), and to the fact that his actions display "a messiah complex, no conscience, and lack complete empathy" (Hoise, 2017).

Trump is however not, by far, the only world leader often accused of displaying an abrasive public persona (on social media, or otherwise). Recent years have seen a renewed focus to the emergence of populist figures worldwide (Albertazzi \& McDonnell, 2008; Mudde, 2004; Mudde \& Rovira Kaltwasser, 2017). Beyond their electoral success and communication strategies (Jagers \& Walgrave, 2007; Mudde, 2007; Nai, 2018), several studies increasingly point to the fact that populists promote a "bad mannered" and "transgressive" political style (Moffitt, 2016; Oliver \& Rahn, 2016) that "emphasises agitation, spectacular acts, exaggeration, calculated provocations, and the intended breech of political and sociocultural taboos" (Heinisch, 2003, p. 94). A recent study by Nai and Martínez i Coma (2019) found that, when compared to "mainstream political figures," populists score lower on agreeableness, emotional stability, and conscientiousness, but score significantly higher on the Dark Triad of narcissism, psychopathy, and Machiavellianism.

Social media bolsters these trends and allow populists to efficiently diffuse their messages (Engesser, Ernst, Esser, \& Büchel, 2017). In this article, however, 
we are not interested in describing how populists communicate on social media, and neither how their image is shaped by it (for this, see, e.g., Ahmadian, Azarshahi, \& Paulhus, 2017; Enli, 2017; Ott, 2017). Rather, we focus on its consequences for the persuasiveness of their messages. Overall-partially contrasting with the contemporary narrative of elections easily swung by (mis)information campaigns on social media-relatively little is known about the persuasive power of political communication on social media (but see Allcott \& Gentzkow, 2017). Even more importantly, little is known about the persuasive power of communication from controversial figures.

\subsection{Persuasion and Affective Polarization}

The dynamics of political persuasion have received strong attention in recent decades (e.g., Cobb \& Kuklinski, 1997; Mutz, Sniderman, \& Brody, 1996). Central in this literature is the idea that persuasion is achieved when individuals are exposed to counterattitudinal messages, that is, messages that clash with their previously held beliefs, and adjust those beliefs accordingly. Inversely, resistance to persuasion exists when "an attitude change is capable of surviving an attack from contrary information" (Petty \& Brinol, 2010, p. 240). Persuasion is endemic in contemporary politics, where voters are exposed to an endless stream of partisan information.

Much attention has been provided to individual differences in resistance to persuasive attempts, for instance in terms of personal relevance of the issue (Petty, Cacioppo, \& Goldman, 1981) or issue-related emotional states (Nai, Schemeil, \& Marie, 2017). Persuasion is also affected by characteristics of the message itself; evidence exists that specific characteristics of the source of the persuasive message also matter, for instance in terms of credibility (Tormala \& Petty, 2004) or likeability (Reinhard \& Messner, 2009) of the source. Especially this last factor-how much the respondent "likes" the source of persuasion-has received a strong attention, confirming a general rationale that liked sources are more likely to persuade, a claim that is central in many dual models of opinion formation (Chaiken, 1980; Petty \& Cacioppo, 1986).

Little is known however about the effects on persuasion effectiveness when information comes from disliked figures (but see Weber, Dunaway, \& Johnson, 2012). Mounting evidence suggests that ideological polarization is being replaced with affective polarization (lyengar, Sood, \& Lelkes, 2012), as disagreements in the public are increasingly driven by a profound dislike for the opponents regardless of their policy alignments. What is increasingly likely to drive the alignment and dealignment of opinions are social identity dynamics of in-group and out-group, where what matters the most is pushing back against the disliked out-group. With this in mind, it is then not surprising to witness that disliked figures have an important role to play in contemporary politics. A substantial part of today's electoral politics can be explained as voting not "for" a specific party or candidate, but rather "against" them; this is one of the main drivers of support for populist and so-called "anti-elitist" parties (Schumacher \& Rooduijn, 2013), and a key element in referenda across the world (Lupia \& Matsusaka, 2004). In this sense, assessing the role of source dislike within persuasive communication is not only epochal due to the growing importance of "antagonistic" figures worldwide-and to get a better sense, ultimately, about how "populist" and other controversial figures manage (or fail to manage) to persuade voters in the first placebut also central for a more complete understanding of the consequences of affective polarization.

\subsection{The Study and the Setting}

In this article, we discuss a theoretical model that explains under which conditions people resist persuasive attempts, and we apply this to an experimental protocol where respondents were exposed to mock tweets from Donald Trump. We test two overarching claims: (1) being confronted to counter-attitudinal information leads to a readjustment of initial opinions (what we call "persuasion"); and (2) cues from a disliked source affect the persuasive power of counter-attitudinal informationmore specifically, persuasion is reduced when the disliked source endorses the counter-attitudinal information, and it is increased when the disliked source opposes the counter-attitudinal information.

We test this model via an experimental protocol where all participants are first asked their opinion about an initial statement (would they support slowing down economic activity to reduce climate warming); depending on their answer, all participants are then exposed to a tailored counter-attitudinal information, that is, information promoting the other side (for instance, reasons why economic activity should be slowed down if they signalled that they would rather not support a slowdown in the first place). After exposure to the counter-attitudinal information, all participants are asked again their opinion about economy slowdown. Divergence between the two statements (pre- and post-counter-attitudinal) indicates readjustment of initial opinions, or persuasion (Nai et al., 2017).

The experimental component intervenes before this second question, just after exposure to the counterattitudinal information. Participants in two experimental groups are exposed to one additional piece of information, framed as a cue form a disliked source (Trump), taking the form of either an endorsement or an opposition to the counter-attitudinal information; a first group is told that the disliked source approves the counterattitudinal information (consonant source cue), whereas the second group is told that the disliked source opposes the counter-attitudinal information (dissonant source cue). Respondents in the control group are only ex- 
posed to the counterargument (no consonant/dissonant source cue). More details about the design are described in Section 3.2.

The experimental components of the protocol-the "disliked source cues" - are based on (mock) tweets from Donald Trump, signalling either support or opposition to the counter-attitudinal piece of information respondents are exposed to. Donald Trump is a perfect subject for real-world experimental research (Resnick, 2018), especially for research on persuasion and likeability. First, he benefits from constant exposure in US and international media, and thus it is fair to assume that he is fairly well known by all respondents, even outside the US as in our case (participants are undergraduate students at the University of Amsterdam). Second, Trump suffers from almost universal dislike outside the US (Wike, Stokes, Poushter, \& Fetterlof, 2017) and its coverage in international media is strongly skewed towards the negative (Patterson, 2017); in this case, he is the perfect realworld candidate for the study on source (un)likeability, as there is a strong chance that recruited participants have already an overall negative opinion about him; as we will see, this is indeed the case. Third, his unique public persona (Nai \& Maier, 2018, 2019; Visser et al., 2017) manifests into frequent opinion shifts on salient issues-for instance, a 2016 Washington Post article (also cited by Resnick, 2018) discusses how Trump publicly took five different positions on abortion in a handful of days (Bump, 2016). This chronic inconsistency is a perk for experimental research, as it allows to create mock statements that are diametrically opposite to fit our treatmentsin our case, mock tweet messages that support opposite stances on climate change. This helps circumvent a well-known limitation in experimental research with realworld figures, that is, the fact that mock treatments have to be consistent with the profile of those figures to be realistic. Given Trump's lack of consistency over important issues, virtually every message and its opposite should be considered at the very least conceivable.

\section{Source Cues and Persuasion}

The starting point of our model is the persuasive power of counter-attitudinal messages. Even in an environment where filter bubbles and selective exposure drive consumption of information that is perceived as congruent with one's own opinions and predispositions (Bakshy, Messing, \& Adamic, 2015; Metzger, Hartsell, \& Flanagin, 2015), people are nonetheless constantly exposed to counter-attitudinal information (Messing \& Westwood, 2014).

People are however hardwired to reject such counterattitudinal information. Following established models of motivated reasoning (Lodge \& Taber, 2000; Taber \& Lodge, 2006), people are driven by directional (or partisan) goals "to apply their reasoning powers in defense of a prior, specific conclusion" (Taber \& Lodge, 2006, p. 756). Initial beliefs "bias" the way citizens respond to partisan information and people tend to evaluate more favorably messages that are in line with their preexisting beliefs ("prior attitude effect"; Taber \& Lodge, 2006); at the same time, people tend to reject counterattitudinal messages.

Nonetheless, if not a full reversal, exposure to counter-attitudinal messages should operate at the very least a readjustment. Following "on-line" information processing models, people keep a "mental tally" of all information encountered about a specific issue; they form judgments as a function of the sequence of information on that issue they are exposed to, and adjust their judgment with any new piece of information received (McGraw, Lodge, \& Stroh, 1990; Redlawsk, 2001, 2002). This adjustment is expected to be stronger for people low in cognitive skills (McGraw et al., 1990), but it is supposed to exist across the board:

$H 1$ : Exposure to counter-attitudinal arguments produces a readjustment of initial opinions.

Many elements intervene to shape the magnitude of this readjustment. In this article, we focus on a previously overlooked element: the presence of supporting information (source cues) advocating for or against the counter-attitudinal messages. More specifically, we argue that resistance to counter-attitudinal information is, first, a direct function of the presence of cues from a disliked source (in our case, an endorsement from Trump), and, second, mediated by the level of cognitive skills of the respondent. We discuss below a theoretical model with two components: (1) the role of consonant disliked source cues on the treatment of counter-attitudinal information; and (2) the role of dissonant disliked source cues on that treatment.

We define a disliked "consonant" source cue as a piece of information provided by an external source (Trump) that is aligned with the content of the persuasive information. Let's take an example, in which a person that usually dislikes burgers is told: (1) that "Big Kahuna burgers are the best burgers in town"; and that (2) Trump very much likes them. The two pieces of information are consistent with each other in the eyes of the respondent (remember that they dislike both those burgers and Trump). The information they receive is "consonant," and because it contrasts with their initially held beliefs the person will probably not have a hard time to reject both. Inversely, a "dissonant" source cue exists when the persuasive message contrasts with the endorsement from the source. In our example, the person is told that Big Kahuna burgers are great, but that Trump dislikes them. In such a case, the two persuasive components of the new information conflict with each other. Both "consonant" and "dissonant" source cues thus only refer to their relationship with the initial persuasive message, and not with the respondent initial beliefs. This is illustrated in Figure 1. The situation would of course be reversed in case of a positively evaluated source cue 


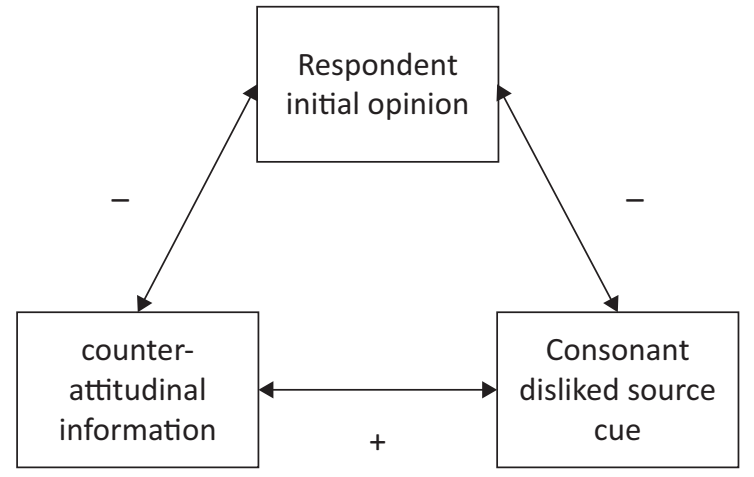

Consistent system of beliefs and information

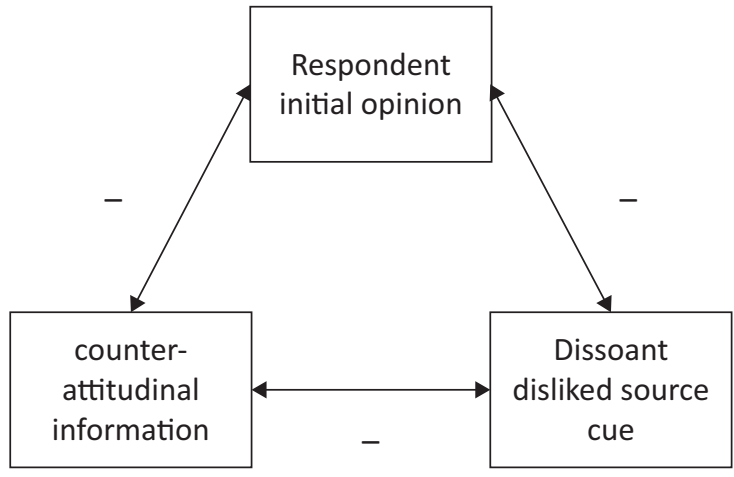

Inconsistent system of beliefs and information

Figure 1. Consistent and inconsistent systems of beliefs and counter-attitudinal information.

(e.g., endorsement of the counter-attitudinal information from a political figure that the respondent likes), but this is not something we test here.

We start with the setting of a consistent system of beliefs and counter-attitudinal information. In this first case, this refers to being exposed to counter-attitudinal information which is endorsed by a disliked figure. We expect that endorsements by disliked sources steal the thunder from persuasive messages. Persuasion is all about convincing the subject that his or her previously held beliefs (if any) are not as anchored as he or she might have believed-opposite rationales exist, the subject might feel, and those rationales actually seem to make sense.

Research shows that persuasion is more likely induced when the source or the sponsor of persuasive messages is liked by the subject (Chaiken, 1980; Petty $\&$ Cacioppo, 1986). The cognitive mechanism supporting this effect, going back to motivated reasoning, is simply a decrease in the automatic defences against counterattitudinal information due to positive feelings towards the source of the message. Within this context, an endorsement by a disliked figure should operate in the other direction. If the default position is to reject information that clashes with our predispositions (Lodge \& Taber, 2000; Taber \& Lodge, 2006) then not only does an endorsement from a disliked figure not mitigate this motivated bias, but it should logically enforce it. In this case, the counter-attitudinal information should be more easily rejected:

$H 2$. Persuasion is less effective when it is endorsed by a disliked figure

The opposite situation is one of an inconsistent system of beliefs and counter-attitudinal information, where individuals are exposed to counter-attitudinal information that is opposed by a disliked figure. In this situation, we expect respondents to experience cognitive dissonance (Festinger, 1962; Harmon-Jones, Harmon-Jones, \& Levy, 2015): They signal a preference for argument A, but are exposed to the new information that a disliked figure also endorses the argument $A$. The clash, in this case, is not external, between predispositions and exogenous persuasion, but rather internal between two sets of beliefs (support for the argument and dislike for the person that also supports that argument). It is not our goal to study the extent of cognitive dissonance in our respondents; rather we expect this mental state to shatter previously held beliefs, paving the way for successful persuasive attempts. Cognitive dissonance robs individuals of their certainties, and thus creates conditions where tailored counterarguments are more likely to be accepted and processed (Harmon-Jones, 2002; Whittaker, 1964). On top of this, there are also reasons to expect that the persuasive message itself is made more palatable in this case. Knowing that Trump rejects a message could suggest that the message itself is not that bad, for those who despise the candidate. The enemy of my enemy is my friend, or in this case the opinion opposed by my enemy might actually be relevant after all:

H3. Persuasion is more effective when it is opposed by a disliked figure.

\section{Methods}

\subsection{Participants}

The experimental survey was administered to a convenience sample of 272 undergraduate students in Communication Science at the University of Amsterdam in October 2017. Students have to collect a given amount of "research credits" during their undergraduate studies (14), and this research provided participants with a modest incentive in this sense $(0.18$ research credits). Convenience samples, especially when composed by such a narrow segment of the population (students) cannot be expected to be representative of the whole population. In this sense, results should not be generalised beyond the boundaries of the sample. This being said, this type of sample has been shown to pose less problems than expected in terms of external valid- 
ity (Druckman \& Kam, 2011). Furthermore, working with student samples offers some specific advantages. For instance, due to their younger age, students tend to have more ductile opinions and predispositions (Lau \& Erber, 1985; Pinkleton, Um, \& Austin, 2002), and thus are good subjects for studies about persuasion. Furthermore, for students age and education effects should cancel each other out (Garramone, 1984).

Unsurprisingly, the sample is far from representative of trends in the general population. In the initial sample before filtering (see below), $84 \%$ of respondents are female (reflecting the composition of students at the University of Amsterdam) and 42\% are Dutch nationals. Although $82 \%$ declared that English is not their main language, the overwhelming majority of participants have an excellent command of English (also reflecting a known characteristics of the Dutch population). On average, respondents are somewhat interested in politics and only averagely knowledgeable about climate change facts; they however declare an average high anxiety about the issue $(M=3.17 / 4, S D=0.94)$. Overall, the sample is slightly skewed towards the left $(M=3.97 / 10, S D=2.03)$.

\subsection{Design and Treatments}

Respondents were randomly assigned to one of three conditions: control group; treatment 1; or treatment 2. All respondents were, first, provided with an introduc- tion presenting some facts about global warming (e.g., that 16 of the 17 warmest years on record occurred since 2001), and then were asked to answer a few factual questions and to report their self-reported emotions when thinking about global warming. The experimental setting followed, introduced for everyone with a short incipit that suggests a potential solution (see Supplementary Material). Figure 2 presents the design of our study at a glance.

After this incipit, all respondents were asked to what extent they support economy slowdown in their country to reduce climate warming (from 0 "Absolutely no" to 10 "Absolutely yes"). This question was used as initial benchmark of the respondents' position and was compared with an identical question after the treatments to gauge opinion change (our main dependent variable, compared across groups). Answers to this initial question were also used to tailor the information that respondents received next; we replicate the design of a previous study (Nai et al., 2017) and provided each respondent with a specific counterargument depending on his or her answer to the initial question. For instance, a respondent that believes that economic activity should be reduced received a counterargument suggesting reasons why this should not be the case. A similar (but reversed) counterargument was proposed to respondents that disagree with economy slowdown. These counterarguments represent the persuasive component of the design.

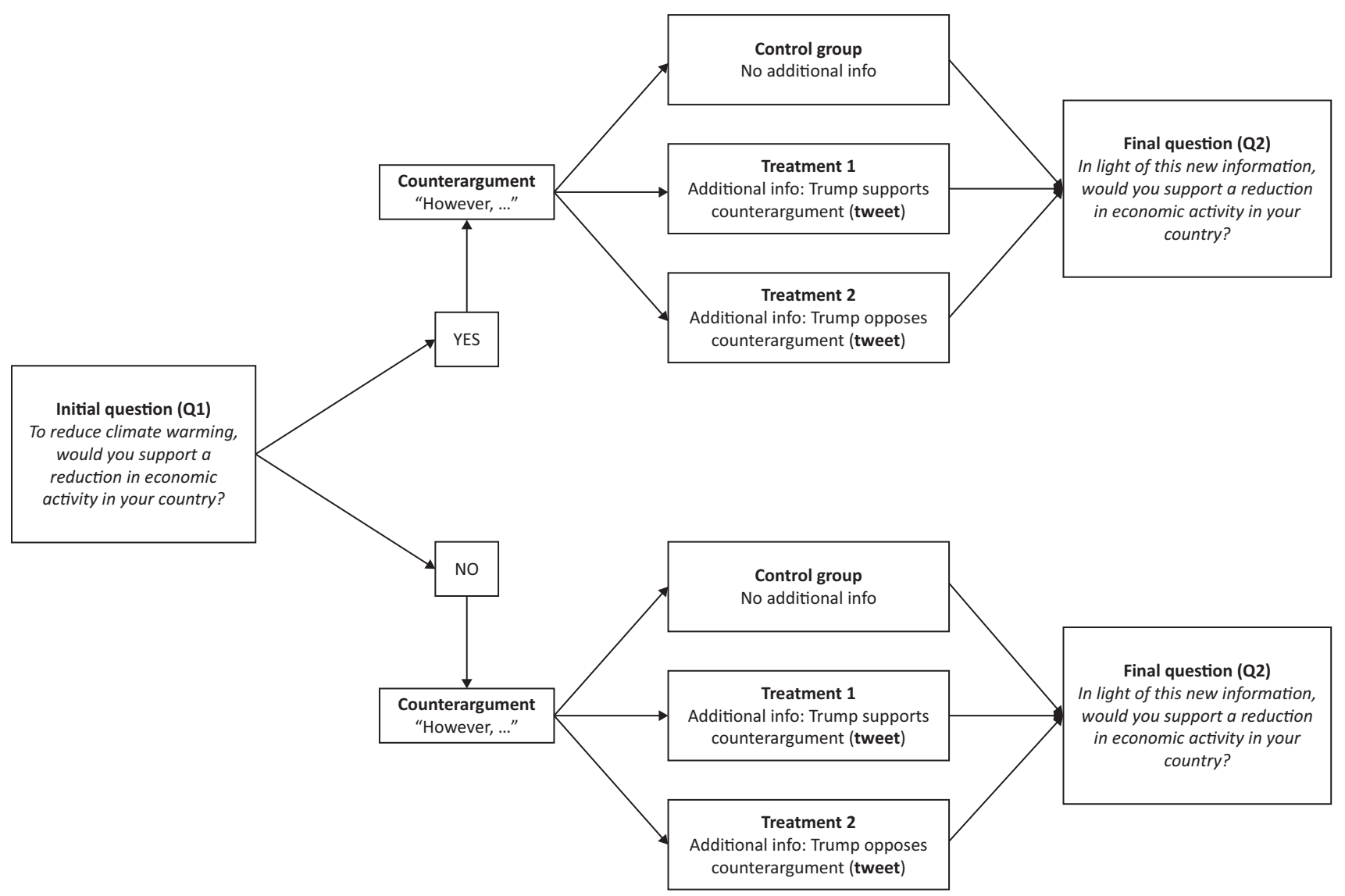

Figure 2. Experimental design. 
After this initial set of information and counterarguments, the experimental component of the study started. Respondents in treatment groups were shown a tweet from Trump either in favour (group 1) or against (group 2) the counterargument, plus a final statement that sums up Trump's position. For instance, respondents that were in favour of economy slowdown were told the following just after the counterargument: "This alternative position is strongly supported by USA President Donald Trump, who recently said in a tweet that climate change is an invention of liberal news media, aiming at reducing the international US competitiveness. Trump thus believes that economic activity should not be reduced" (see Figure 3a). Similarly, respondents that believe that economic activity should not be reduced were exposed to a mock tweet that supports the opposite position. After this treatment, respondents were asked again to evaluate, in the light of this new information, whether they support economy slowdown.

The second treatment was similar but reversed. In this case respondents in the treatment groups, after being exposed to the counterargument, were shown a tweet where Trump signals his opposition to that counterargument. The questionnaire, including the mock tweets used as treatment, is in the Supplementary Material. Respondents in the control group were not provided with any further information.

Figure 3 presents the two mock Trump tweets that were used in the experiment. Figure $3 a$ shows the mock tweet where Trump opposes economic slowdown, whereas Figure $3 b$ shows the mock tweet where Trump supports the slowdown. The tweets are similar in length. They differ of course in the topics presented; the first refers to US manufacturing sector whereas the second refers to China and the issue of pollution. However, the two tweets are extremely similar in framing and tone; both tweets refer to "fake news media" - one of Trump's most known catchphrases-make a similar use of capitalization of selected works (HOAX, STOP) and exclamation marks, which are also a distinctive trait of Trump's social media use, and use a very similar direct and "low" language (Ostiguy, 2009). In this sense, the tweets have many more elements in common than elements that differentiate them and can in our opinion be seen as rather comparable-beyond of course their main difference in the position advocated, which is the experimental component we use in our group comparisons.

\subsection{Opinion Change}

The dependent variable in all our analyses-opinion change after persuasion-is measured by comparing answers to the question "Do you support economy slowdown?" before and after the treatment. We subtracted the score at the first question from the score at the second question. The higher the score, the higher the change in opinions after exposure to counterarguments; positive scores signal a stronger agreement to economy slowdown after treatment, whereas negative scores signal a stronger disagreement. Descriptive statistics are presented in Table A1 in the Supplementary Material; the table excludes respondents that are filtered out-see Section 3.4.

\subsection{Filters}

We employ two filters. The first one ensures that our analyses are run only on respondents that dislike Trump. Before the experiment, a battery of questions asked all respondents to evaluate a series of public figures (Julian Assange, Donald Trump, Geert Wilders, Hillary Clinton, Pope Francis, Rihanna, and Vladimir Putin), presented in a random order, using the feeling thermometer developed by the ANES research group (Wilcox, Sigelman, \& Cook, 1989) on a 0-100 scale. Unsurprisingly, the average "warmth" for Trump over the whole sample is extremely low ( $M=9.86, S D=13.94)$-almost half of the average score for the next most disliked figure in our battery, Putin ( $M=18.62, S D=20.98)$. The higher average "warmth" is for Rihanna ( $M=65.54, S D=21.05)$, followed by the Pope ( $M=52.94, S D=21.42)$. To ensure that only respondents that dislike Trump are included in the final sample, we dropped all respondents whose warmth for the candidate was higher than 30 out of 100 . (a) (b)

Donald J. Trump
@realDonaldTrump
The fake news media say I am against "climate
change", but that's a lie. Look at China!
Pollution and disease. Sad! Be smart, STOP
producing so much!
RERTEETS LIKES
8,866 37,082
6:23 AM - 18 Mar 2017

Figure 3. Mock tweets (treatments). (a) Trump mock tweet (against slowdown), (b) Trump mock tweet (in favour of slowdown). 
The second filter is a screener (or "attention check"; Berinsky, Margolis, \& Sances, 2014) set up as long question with specific instructions "hidden" in the middle (in our case, to simply chose the option "other" and write "dinosaur" in the allowed space). Respondents that failed to comply with those instructions are assumed to only having skimmed the questions and are filtered out. After excluding respondents that either do not have a strong dislike for Trump (19) or that fail the attention check (71), our final sample is composed of 199 respondents.

\section{Results}

The first clear result is that persuasion works. At different degrees, and depending on the experimental conditions, all results converge towards the fact that, when exposed to a counter-attitudinal argument, respondents on average readjust their prior opinions. Figures 4 and 5 show this trend: Respondents that had an initial opinion in favour of economy slowdown are less likely to support it when exposed to counter-attitudinal information (e.g., Figure 4a); in the same way, respondents that were initially against economy slowdown are more likely to think that it is a good idea when exposed to counter-attitudinal information (e.g., Figure 4b). We now test under which conditions this is more likely to happen, looking at the congruence of source cues.

(a)

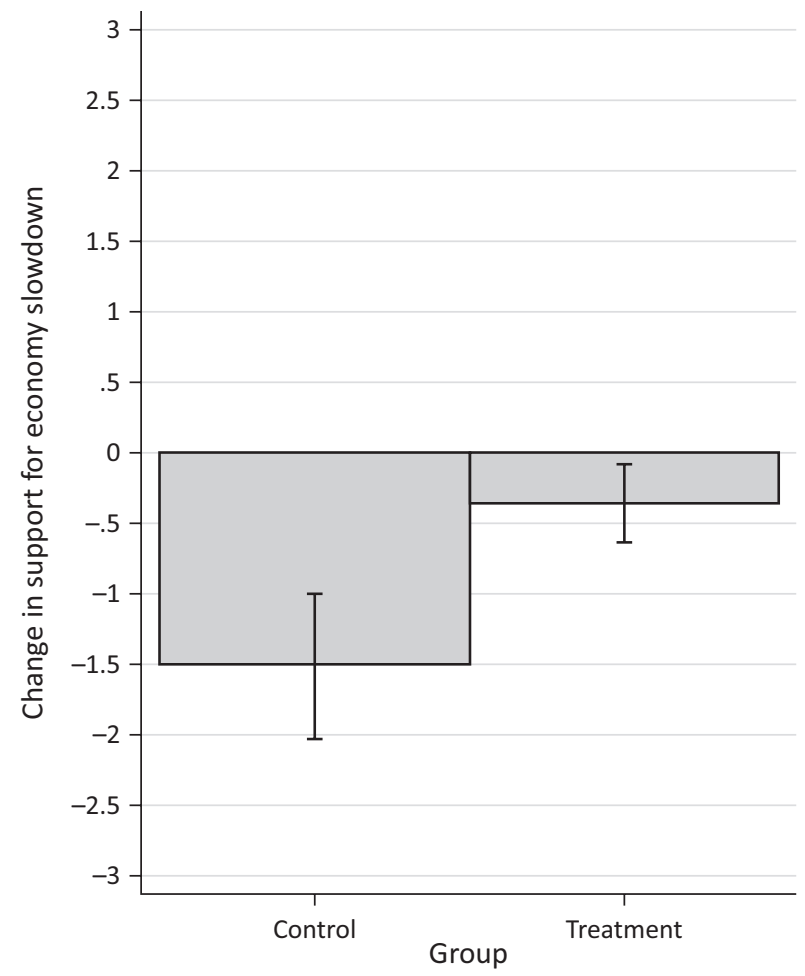

\subsection{Trump Agrees with the Persuasive Message}

We first test the assumption that the persuasive power of counterarguments is stripped away when they are supported by a disliked figure (in our case, Trump). Figure 4 contrasts the mean opinion change score for respondents in the control group with the mean score for respondents that have been told that Trump supports the counterargument. Figure $4 a$ is for respondents that declared an initial support for economy slowdown (and thus received a counterargument that tried to convince them that the slowdown would be ineffective and potentially harmful), whereas Figure $4 \mathrm{~b}$ is for respondents that initially rejected the idea of economy slowdown. Remember that due to variables coding higher positive scores on the dependent variable (y-axis) signal a move towards increased agreement towards the slowdown, whereas high negative scores signal a move towards increased disagreement.

Let's first observe respondents that initially agreed with economy slowdown as a solution of global warming (Figure 4a). For those respondents, we find strong confirmation of our expectation. Compared to the control group, the group that was told that Trump agrees with the counterargument was significantly less likely to change their opinion. The difference between the two groups is important and statistically significant, $t(77)=-4.16, p<0.001, d=0.95$. A similar trend can

(b)

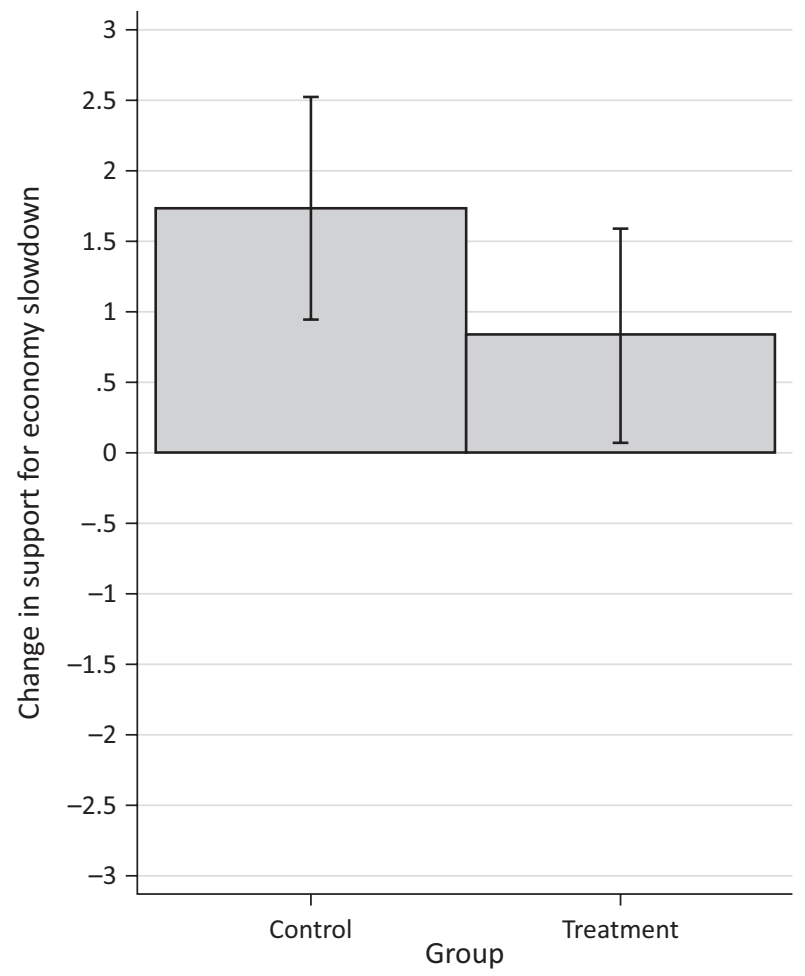

Figure 4. Treatment 1 effects: Trump "agrees" with the persuasive message. (a) Initially in favour of economy slowdown, (b) Initially against economy slowdown. Notes: $\mathrm{N}$ (control) $=37, \mathrm{~N}$ (treatment) $=42$ (Figure $4 \mathrm{a}) ; \mathrm{N}($ control) $=26$, $\mathrm{N}$ (treatment) $=23$ (Figure $4 \mathrm{~b})$. 
be observed as well for respondents that initially opposed economy slowdown (Figure $4 \mathrm{~b}$ ): Being told that Trump supports the persuasive argument makes respondents less likely to change their opinion when compared with the control group. The difference between the two groups is only significant at $10 \%$ and less dramatic than in Figure $4 a, t(47)=1.70, p<0.096, d=0.50$. Overall, this suggests that people are more likely to resist persuasion when the persuasive message is endorsed by despised figures. This provides a contrario confirmation that source likeability also works in reverse: Dislike drives resistance to persuasion.

\subsection{Trump Disagrees with the Persuasive Message}

The second treatment reverses the logic of the first, and deals with the effects of dissonant disliked source cues. In lay language, instead of supporting the counterattitudinal information as in the first treatment here Trump opposes it (and, thus, he supports the respondent's initial position). The intuition here is that respondents will be more likely to accept the persuasive information if they are informed that Trump opposes it. Our results show only partial support of this expectation (Figure 5).

Contrarily to what expected, respondents that initially agree with economy slowdown (Figure 5a) in the control group do not have stronger levels of opinion

(a)

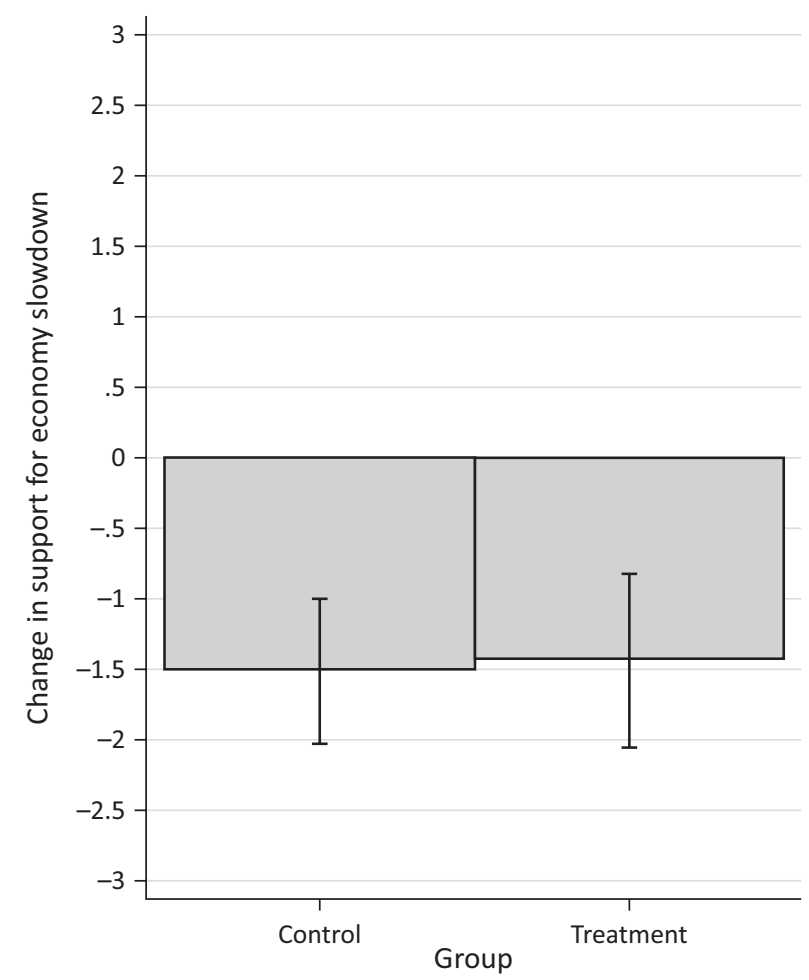

change (which would mean that they disagree more with economy slowdown after being exposed to the counterargument) than respondents in the control group, $t(74)=-0.10, p=0.846$. The absence of difference between the two groups mean that being told that a disliked figure (Trump) opposes a persuasive message does not makes more likely for this persuasive message to be effective and result in opinion change. The figure offers however a striking contrast with respondents that have been exposed with the first treatment (Figure 4a), as discussed before. Figure $5 b$ shows trends that are in the direction of our expectations-for respondents that initially disagree with the slowdown, being told that Trump opposes the persuasive argument makes respondents slightly more likely to be persuaded and change their opinion. The difference between the two groups is, however, again not statistically significant, $t(42)=-0.65, p=0.519$.

\section{Discussion and Conclusion}

Societal conflict lines are increasingly drawn based on how much we dislike our opponents, and less so on how much we disagree with their policy proposals. Assessing the extent of this "affective polarization," lyengar et al. (2012) show, for instance, that in the USA over the past 50 years the use of negative stereotypes to describe the opponents (e.g., mean, hypocritical, selfish, closedminded) has increased exponentially. Within this set-

Figure 5. Treatment 2 effects: Trump "disagrees" with the persuasive message. (a) Initially in favour of economy slowdown, (b) Initially against economy slowdown. Notes: $\mathrm{N}$ (control) $=37, \mathrm{~N}$ (treatment) = 39 (Figure 5a); $\mathrm{N}($ control) $=26$, $\mathrm{N}$ (treatment) $=18$ (Figure $5 \mathrm{~b})$. 
ting, it is thus perhaps unsurprising that controversial figures thrive. Agitators, provocateurs, and bad-mannered, populists have their moment in the spotlight and, in some cases, in governments worldwide (Nai \& Martínez i Coma, 2019). The increasing affective polarization and consolidation of controversial figures raises a fundamental question: To what extent is the success of (populist) persuasive messages a function of their affective assessment by the public at large? In this article, we explored this overarching question via an experimental setting where respondents in a Dutch student sample were exposed to persuasive tailored counterarguments to their expressed opinion (on climate change), and subsequently exposed to cues-either in favour or against the counterarguments-from a disliked figure, and one of the most illustrious examples of the current populist zeitgeist: Donald Trump.

In a nutshell, our results suggest that: (1) persuasion works-at different degrees, and depending on the experimental conditions, respondents on average readjust their prior opinions when they are exposed to a counterattitudinal argument; (2) positive endorsements from a disliked source reduce the persuasive power of counterattitudinal information (being told that Trump supports the persuasive argument makes respondents less likely to change their opinion); and (3) negative endorsements from a disliked source increase the persuasive power of counter-attitudinal information (being told that Trump opposes the persuasive argument makes respondents slightly more likely to be persuaded and change their opinion-although not is a significant way).

All in all, our results show that the persuasive power or counter-attitudinal information exists as a function of (positive or negative) endorsement from disliked sources. This suggests that endorsements matter in political propaganda, and that the persuasive power of arguments can be manipulated by external sources.

Much has been said already about the 2016 Presidential election in the media and academic debates. A leitmotif, at least in liberal circles, was that many Trump supporters uncritically accepted, shared and processed low-quality anti-Clinton propaganda and "fake news" (Allcott \& Gentzkow, 2017), which might have increased his electoral appeal. Our results suggest that a similar phenomenon could be at play also among detractors of the current President: A simple endorsement from Trump (positive or negative) substantially alters how issue-based messages are perceived, regardless of their direction, valence, and content. This being said, the question remains open about the political implications of this effect, and about why many (on both sides of the partisan divide) seem to forego most critical skills when it comes to the current US president (Nai \& Maier, 2019).

\section{Acknowledgments}

We are very grateful to the three anonymous reviewers, journal editors and Cristine de Clercy, editor of the the- matic issue, for their support, critical assessment, and constructive suggestions. We take of course full responsibility for any remaining mistakes. A previous version of this article was presented at the 2019 annual meeting of the International Communication Association (ICA, Washington, DC, May 2019). Many thanks to all the students who took part in the experiment. The experiment received full approval from the Ethics Review Board of the Faculty of Social and Behavioral Sciences, University of Amsterdam (ref. 2017-PCJ-8409) on October 18, 2017.

\section{Conflict of Interests}

The author declares no conflict of interests.

\section{Supplementary Material}

Supplementary material for this article is available online in the format provided by the authors (unedited).

\section{References}

Ahmadian, S., Azarshahi, S., \& Paulhus, D. L. (2017). Explaining Donald Trump via communication style: Grandiosity, informality, and dynamism. Personality and Individual Differences, 107, 49-53.

Albertazzi, D., \& McDonnell, D. (Eds.). (2008). Twentyfirst century populism: The spectre of Western European democracy. Houndmills: Palgrave.

Allcott, H., \& Gentzkow, M. (2017). Social media and fake news in the 2016 election. Journal of Economic Perspectives, 31(2), 211-236.

Bakshy, E., Messing, S., \& Adamic, L. A. (2015). Exposure to ideologically diverse news and opinion on Facebook. Science, 348(6239), 1130-1132.

Berinsky, A. J., Margolis, M. F., \& Sances, M. W. (2014). Separating the shirkers from the workers? Making sure respondents pay attention on self-administered surveys. American Journal of Political Science, 58(3), 739-753.

Bump, P. (2016, April 3). Donald Trump took 5 different positions on abortion in 3 days. The Washington Post. Retrieved from https://www.washingtonpost. com/news/the-fix/wp/2016/04/03/donald-trumpsever-shifting-positions-on-abortion/?utm_term= $.595100 \mathrm{c} 8 \mathrm{f} 5 \mathrm{fO}$

Chaiken, S. (1980). Heuristic versus systematic information processing and the use of source versus message cues in persuasion. Journal of Personality and Social Psychology, 39(5), 752-766.

Cobb, M. D., \& Kuklinski, J. H. (1997). Changing minds: Political arguments and political persuasion. American Journal of Political Science, 41(1), 88-121.

Druckman, J. N., \& Kam, C. D. (2011). Students as experimental participants: A defense of the 'narrow data base.' In J. N. Druckman, D. P. Green, J. H. Kuklinski, \& A. Lupia (Eds.), Cambridge handbook of experimental political science (pp. 41-57). Cambridge: Cambridge 
University Press.

Engesser, S., Ernst, N., Esser, F., \& Büchel, F. (2017). Populism and social media: How politicians spread a fragmented ideology. Information, Communication \& Society, 20(8), 1109-1126.

Enli, G. (2017). Twitter as arena for the authentic outsider: Exploring the social media campaigns of Trump and Clinton in the 2016 US presidential election. European Journal of Communication, 32(1), 50-61.

Festinger, L. (1962). A theory of cognitive dissonance. Stanford, CA: Stanford University Press.

Garramone, G. M. (1984). Voter responses to negative political ads. Journalism Quarterly, 61(2), 250-259.

Harmon-Jones, E. (2002). A cognitive dissonance theory perspective on persuasion. In J. P. Dillard \& M. Pfau (Eds.), The persuasion handbook: Developments in theory and practice (pp. 99-116). New York, NY: Sage.

Harmon-Jones, E., Harmon-Jones, C., \& Levy, N. (2015). An action-based model of cognitive-dissonance processes. Current Directions in Psychological Science, 24(3), 184-189.

Heinisch, R. (2003). Success in opposition-Failure in government: Explaining the performance of right-wing populist parties in public office. West European Politics, 26(3), 91-130.

Hoise, R. (2017, February 2). The deeper reason we should be worried Donald Trump hung up on Australia PM Malcolm Turnbull. Independent. Retrieved from https://www.independent.co.uk/lifestyle/health-and-families/donald-trump-mentalhealth-why-worry-hung-up-australia-pm-malcolmturnbull-psychological-world-a7559461.html

Iyengar, S., Sood, G., \& Lelkes, Y. (2012). Affect, not ideology: A social identity perspective on polarization. Public Opinion Quarterly, 76(3), 405-431.

Jagers, J., \& Walgrave, S. (2007). Populism as political communication style: An empirical study of political parties' discourse in Belgium. European Journal of Political Research, 46(3), 319-345.

Lau, R. R., \& Erber, R. (1985). Political sophistication: An information-processing perspective. In S. Kraus \& R. M. Perloff (Eds.), Mass media and political thought (pp. 37-64). Beverly Hills, CA: Sage.

Lodge, M., \& Taber, C. S. (2000). Three steps toward a theory of motivated political reasoning. In A. Lupia, M. D. McCubbins, \& S. L. Popkin (Eds.), Elements of reason: Cognition, choice, and the bounds of rationality (pp. 183-213). New York, NY: Cambridge University Press.

Lupia, A., \& Matsusaka, J. G. (2004). Direct democracy: New approaches to old questions. Annual Review of Political Science, 7, 463-482.

McAdams, D. P. (2016). The mind of Donald Trump. The Atlantic. Retrieved from https://www.theatlantic. com/magazine/archive/2016/06/the-mind-ofdonald-trump/480771

McGraw, K. M., Lodge, M., \& Stroh, P. (1990). On-line processing in candidate evaluation: The effects of issue order, issue importance, and sophistication. Political Behavior, 12(1), 41-58.

Messing, S., \& Westwood, S. J. (2014). Selective exposure in the age of social media: Endorsements trump partisan source affiliation when selecting news online. Communication Research, 41(8), 1042-1063.

Metzger, M. J., Hartsell, E. H., \& Flanagin, A. J. (2015). Cognitive dissonance or credibility? A comparison of two theoretical explanations for selective exposure to partisan news. Communication Research. Advance online publication. https://doi.org/10.1177/ 0093650215613136

Moffitt, B. (2016). The global rise of populism: Performance, political style, and representation. Stanford, CA: Stanford University Press.

Mudde, C. (2004). The populist Zeitgeist. Government and Opposition, 39(4), 542-563.

Mudde, C. (2007). Populist radical right parties in Europe. New York, NY: Cambridge University Press.

Mudde, C., \& Rovira Kaltwasser, C. (2017). Populism: A very short introduction. New York, NY: Oxford University Press.

Mutz, D. C., Sniderman, P. M., \& Brody, R. A. (1996). Political persuasion and attitude change. Ann Arbor, MI: University of Michigan Press.

Nai, A. (2018). Fear and loathing in populist campaigns? Comparing the communication style of populists and non-populists in elections worldwide. Journal of Political Marketing. https://doi.org/10.1080/15377857. 2018.1491439

Nai, A., \& Maier, J. (2018). Perceived personality and campaign style of Hillary Clinton and Donald Trump. Personality and Individual Differences, 121, 80-83.

Nai, A., \& Maier, J. (2019). Can anyone be objective about Donald Trump? Assessing the personality of political figures. Journal of Elections, Public Opinion \& Parties. https://doi.org/10.1080/17457289.2019.1632318

Nai, A., \& Martínez i Coma, F. (2019). The personality of populists: Provocateurs, charismatic leaders, or drunken dinner guests? West European Politics, 42(7), 1337-1367.

Nai, A., Schemeil, Y., \& Marie, J.-L. (2017). Anxiety, sophistication, and resistance to persuasion: Evidence from a quasi-experimental survey on global climate change. Political Psychology, 38(1), 137-156.

Oliver, J. E., \& Rahn, W. M. (2016). Rise of the Trumpenvolk: Populism in the 2016 election. The ANNALS of the American Academy of Political and Social Science, 667(1), 189-206.

Ostiguy, P. (2009). The high and low in politics: A twodimensional political space for comparative analysis and electoral studies (Working Paper 360). Notre Dame, IN: Kellogg Institute for International Studies.

Ott, B. L. (2017). The age of Twitter: Donald J. Trump and the politics of debasement. Critical Studies in Media Communication, 34(1), 59-68.

Patterson, T. E. (2017). News coverage of Donald Trump's first 100 days. Shorenstein Center. Retrieved 
form https://shorensteincenter.org/news-coveragedonald-trumps-first-100-days

Petty, R. E., \& Brinol, P. (2010). Attitude change. In R. F. Baumeister \& E. J. Finkel (Eds.), Advanced social psychology: The state of the science (pp. 217-259). New York, NY: Oxford University Press.

Petty, R. E., \& Cacioppo, J. T. (1986). Communication and persuasion: Central and peripheral routes to attitude change. New York, NY: Springer.

Petty, R. E., Cacioppo, J. T., \& Goldman, R. (1981). Personal involvement as a determinant of argumentbased persuasion. Journal of Personality and Social Psychology, 41(5), 847-855.

Pinkleton, B. E., Um, N. H., \& Austin, E. W. (2002). An exploration of the effects of negative political advertising on political decision making. Journal of Advertising, 31(1), 13-25.

Redlawsk, D. P. (2001). You must remember this: A test of the on-line model of voting. The Journal of Politics, 63(1), 29-58.

Redlawsk, D. P. (2002). Hot cognition or cool consideration? Testing the effects of motivated reasoning on political decision making. Journal of Politics, 64(4), 1021-1044.

Reinhard, M. A., \& Messner, M. (2009). The effects of source likeability and need for cognition on advertising effectiveness under explicit persuasion. Journal of Consumer Behaviour, 8(4), 179-191.

Resnick, B. (2018, July 19). Trump is a real-world political science experiment. VOX. Retrieved from https:// www.vox.com/science-and-health/2017/10/11/ 16288690/trump-political-science-psychologyfollow-the-leader
Schumacher, G., \& Rooduijn, M. (2013). Sympathy for the 'devil'? Voting for populists in the 2006 and 2010 Dutch general elections. Electoral Studies, 32(1), 124-133.

Taber, C. S., \& Lodge, M. (2006). Motivated skepticism in the evaluation of political beliefs. American Journal of Political Science, 50(3), 755-769.

Tormala, Z. L., \& Petty, R. E. (2004). Source credibility and attitude certainty: A metacognitive analysis of resistance to persuasion. Journal of Consumer Psychology, 14(4), 427-442.

Visser, B. A., Book, A. S., \& Volk, A. A. (2017). Is Hillary dishonest and Donald narcissistic? A HEXACO analysis of the presidential candidates' public personas. Personality and Individual Differences, 106, 281-286.

Weber, C., Dunaway, J., \& Johnson, T. (2012). It's all in the name: Source cue ambiguity and the persuasive appeal of campaign ads. Political Behavior, 34(3), 561-584.

Whittaker, J. O. (1964). Cognitive dissonance and the effectiveness of persuasive communications. Public Opinion Quarterly, 28(4), 547-555.

Wike, R., Stokes, B., Poushter, J., \& Fetterlof, J. (2017). U.S. image suffers as publics around world question Trump's leadership. Pew Research Center. Retrieved from http://www.pewglobal.org/2017/06/26/u-simage-suffers-as-publics-around-world-questiontrumps-leadership

Wilcox, C., Sigelman, L., \& Cook, E. (1989). Some like it hot: Individual differences in responses to group feeling thermometers. Public Opinion Quarterly, 53(2), 246-257.

\section{About the Author}

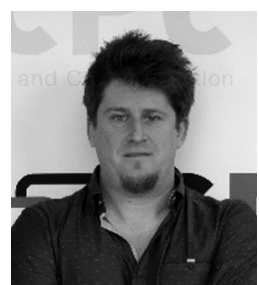

Alessandro Nai is Assistant Professor of Political Communication and Journalism at the Department of Communication Science, University of Amsterdam. His recent work has been published in journals such as Political Psychology, European Journal of Political Research, West European Politics, Government \& Opposition, European Political Science, Personality and Individual Differences, Presidential Studies Quarterly, Electoral Studies, Journal of Political Marketing, and more. He co-edited the volumes New Perspectives on Negative Campaigning: Why Attack Politics Matters (ECPR Press, 2015, with Annemarie S. Walter) and Election Watchdogs (Oxford University Press, 2017, with Pippa Norris). He is currently Associate Editor of the Journal of Social and Political Psychology. 